\title{
Perception of Aggressiveness of Communicative Information Depending on a Speaker's Gender
}

\author{
Anastasia A. Kuzminykh and Sergey N. Enikolopov
}

\begin{abstract}
Despite the great attention to the study of aggression in general, today we can see surprisingly small amount of research on the perception of aggression. Current work was inspired by the results of our previous study about prevailing perceptions of masculine and feminine aggression that showed that in general men are believed to be more aggressive, but also both for men and for women there is a tendency to consider their own aggressiveness as more high than it is in perception of the opposite gender and in general women evaluate both genders as more aggressive than men do. We were interested whether these beliefs about male and female aggressiveness will find reflection in the direct perception of communicative information. We created a computer program, consisting of the page for demographic information and the experimental part - a set of 20 aggressive and 16 non-aggressive audio phrases presented in male and female voices. It has been shown that women in general evaluate phrases as more negative, than men do, but non-aggressive phrases are perceived by women as more friendly when they are said in male voice.
\end{abstract}

Index Terms-Aggression, aggressiveness, gender differences, perception.

\section{INTRODUCTION}

In the modern world saturated with everyday communication in a variety of contexts, more and more areas of knowledge, both scientific and practical, recognize the importance of studying the phenomenon of aggression. Some researchers define aggression as any form of behavior aimed at causing someone physical or psychological harm [1] or causing physical harm to another subject, who is motivated to avoid this effect [2], other authors understand aggression as any form of behavior that aimed at insulting or causing harm to another living being, who does not want such treatment [3] However, the common and fundamentally important part of any definition of aggression is an indication of the psychological evaluation of the aggressive act by a victim, because to be really aggressive, action must not only be executed, but also be perceived as such.

For today a lot of research on the motivational components and specific of demonstration of behavioral aggression are accumulated, as well as studies on the structure and expression of aggressiveness. At the same time, despite the fact that the perception of communicative messages and, in

Manuscript received November 8, 2013; revised January 22, 2014.

A. A. Kuzminykh was with Lomonosov Moscow State University, Moscow, Russia. She is now with the University of Waterloo, Waterloo, Canada (e-mail: akuzminy@uwaterloo.ca).

S. N. Enikolopov is with Lomonosov Moscow State University, Moscow, Russia and with the Department of Legal Psychology, Moscow State University of Psychology and Education, Moscow, Russia (e-mail: enikolopov@mail.ru). particular, the assessment of aggressiveness of coming interpersonal information plays an important role in the process of interaction, research on the perception of aggression is still remains a relatively new field.

Research in this area promises to significantly increase an understanding of the phenomenon of aggression and mechanisms of behavioral phenomena that are directly associated with it.

\section{TYPES OF AGGRESSION}

Due to the breadth of the field of study, there are a large number of classifications of aggression. R. Baron and D. Richardson [3] distinguish hostile aggression, aimed at causing suffering, and instrumental aggression, where harm is not the goal but the resource of achieving a desired result. K. Dodge and J. Coie [4] proposed the concept of reactive aggression as a reaction to the perceived threat, and proactive aggression as the cause of behavior that directed at obtaining a positive result. S. Feshbah distinguishes expressive aggression, describing it as a spontaneous, unfocused, quickly fading burst of anger, hostile aggression, the purpose of which is to harm, and instrumental aggression, which is a means of achieving a neutral result [5], [6].

Today, the scientific community has reached a consensus taking the position that there are at least two broad categories of aggression: first is a hostile, affective, response aggression, directed against the second type - instrumental, predatory or intentional aggression [1], [7]-[9].

Also it is quite common to distinguish between acts of aggression on the basis of their implementation and direction. If the action directly aimed against any object or person (such as beating, shouting at someone) it is classified as direct aggression. Indirect aggression includes acts that are not directly focused on the other person, for example, gossips, bad jokes or slander, as well as acting disorderly. Verbal aggression shows itself in the form of inflicting psychological harm predominantly by using vocal (volume and tone of voice) and verbal components (threat, curse). Physical aggression involves using physical force against another person or object. A. Buss distinguishes four types of physical and four types of verbal aggression on the bases of its activity (active / passive) and direction (direct / indirect) [10].

Moreover, we should highlight the consideration of aggressiveness as a personality trait that reflects the tendency to use aggression to achieve one's goals [6]. Such a separation of the concepts of aggression as behavior and aggressiveness as a trait is extremely important for understanding the nature of the structure of the phenomenon of aggression. For example, K. Izard [11], noting that aggressive behavior is 
usually caused by a number of factors - cultural, family, individual, points to the results of studies that show that aggressive children, when they grow up, as a rule, also exhibit aggressive or criminal behavior. Based on this, Izard suggests that the level of aggressiveness is an innate characteristic of an individual and as person grows older acquires the character of a stable personality trait. There is a lot of research, confirming the validity of this assumption. For example, G. Roth and D. Strüber [12] found that aggressive children from an early age show temperamental differences that contribute to the development of ways to reactive or proactive aggression later in life.

\section{GENDER DIFFERENCES IN AGGRESSION}

It is known that sex differences are reflected in the morphological and functional organization of the brain structures, what is demonstrated in the individual characteristics, for example, specific of attention, and behavior as a whole [13]. For the differences in aggressive acts it mentions in the literature that men tend to use more direct and, often, physical aggression, when for women indirect or verbal aggression is more typical [5]. J. Archer believes that direct, especially physical aggression in general more often than other types of aggression can be found in both men and women of all ages and in different cultures. It begins to manifest itself in early childhood, reaching a peak between 20 and 30 years [14]. A. Eagly and B. Steffen regard the differences in aggression from the point of view of gender roles that encourage some forms of demonstration of aggression in men, while it is discouraged in women [15]. This situation may force a man to demonstrate aggression when in his eyes his passivity can be evaluated negatively. On the contrary, a woman can expect social disapproval for the demonstration of aggression. It has been shown that the tendency of men to demonstrate higher levels of aggression more likely to appear after a strong provocation than without it. Also, some results show that at the age of ten for the same aggressive behavior boys expect less disapproval from their parents than girls [16], [17].

In an effort to understand the relationship between biological and social factors in differences of male and female aggression, scientists often resort to cross-cultural, evolutionary studies and studies with children. K. Bjorkqvist notes that women of different cultures have different ways of non-physical aggression toward their husbands [18]. On the Bellona Island, where male dominance is culturally fixed, women come into conflict with each other much more frequently than with men. However, if there is a conflict between wife and husband, instead of showing the physical aggression a woman resorts to a particular tradition - she composes a song that mocks her husband, and then distributes it all over the island. In this example the aggression takes an indirect form, as the woman does not put herself in the face of an immediate danger.

Social norms of the middle class in the European and North American cultures do not encourage demonstration of physical aggression in adult men [19]. At the same time, comparing the levels of crime and types of crime in both genders for different years, and looking at them in relation to the historical changes of the social role of men and women, L. Berkowitz came to the conclusion that there is no reason to talk about closing the gap on women's and men's crime in parallel with the erasure of the boundaries between male and female social roles [1]. It also has been shown that up to three years age an aggressive behavior of boys and girls is mostly identically and the physical, verbal and indirect aggression in both genders are in equal proportions. But by four years age boys start mostly fighting, and girls are crying and screaming [20]. Among biologists who study social behavior, there is the theory that gender differences in aggression are mainly caused by genetic factors, as in the past physically aggressive behavior gave men the opportunity to pass on their genes to the next generation, resulting in today's men are more prone to physical aggression [16].

\section{GENDER DIFFERENCES IN AGGRESSIVENESS}

Previously it was assumed that high testosterone levels are associated with higher levels of men aggressiveness. By now it has been shown that high level of testosterone itself is not a sufficient precondition for aggression [21], and aggressive behavior, which correlates with high levels of testosterone, is associated mainly with the desire to maintain the dominance [22]. P. Gray in several studies [23], [24] has shown that marriage and fatherhood reduces testosterone levels. A little bit later the Swiss team led by E. Abbott [25] has debunked the general idea of the role of testosterone in increasing aggressiveness. At the same time, F. Brambilla and colleagues [26] concluded that hormone secretion and its fluctuations may still modulate some physiological aspects of behavioral parameters. Thus, the role of hormones in aggressiveness levels is under review.

Some social research indicates a higher likelihood of abuse by men than by women. S. Bennett and colleagues [27] attribute this to gender differences in the perception of social information, based on the fact that a person's response to a stressful event will depend on how he sees and evaluates the event. Such an assessment of the situation and its specifics is directly related to the characteristics of the cognitive processes of the individual. Today in the literature we also can come across evidence that the in Western heterosexual partnerships women can use physical acts of aggression slightly more likely than men [28], when among non-Western countries the situation is opposite [29]. However, it is important to take into account that men generally demonstrate less victimization and do not consider women's aggression against them as criminal [30].

\section{THE MOtivation FOR THE STUDY}

Previously [31], we conducted a study that aimed to examine the prevailing ideas about male and female aggression and aggressiveness among the Russian-speaking population of Russia and CIS countries.

After surveying 541 people aged 12 to 81 years, we found that the vast majority of surveyed people recognize the difference in male and female aggression. A relatively small percentage of surveyed people mentioned physical aggression in women or mentioned it only for extreme cases, 
while in men physical aggression was recognized as typical. For women an indirect aggression, such as gossips, scandals or psychological pressure was recognized as typical.

Also, an interesting peculiarity of men's and women's perception of each other's aggressiveness was discovered.

More women than men perceive the level of male aggressiveness as very high, while the men themselves rated their level of aggressiveness, mainly as negligible. Also men assessed women as non-aggressive more often than women themselves. Women are more likely than men rated their level of aggressiveness as very high. Most of the men evaluated female level of aggressiveness as low, and for women the peak of responses occurred at the answers "rather high" and "neutral" (Fig. 1, combined with Table I).

Based on these results we can see that both for men and for women there is a slight tendency to consider their own aggressiveness as more high than it is in perception of the opposite gender.

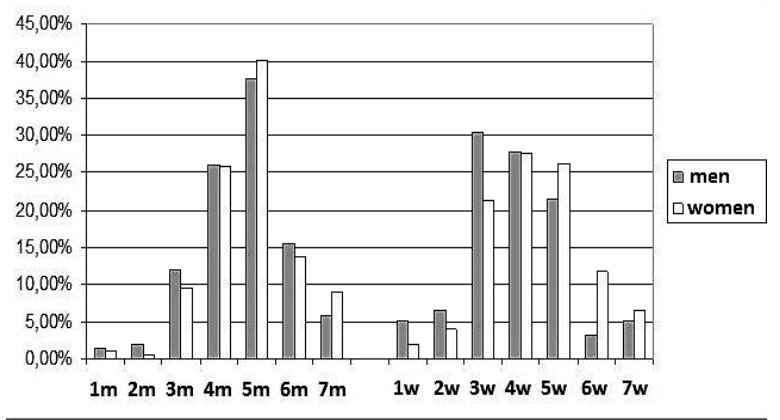

Fig. 1. Levels of male and female aggressiveness.

TABLE I: ABBREVIATIONS USED IN FIG. 1

\begin{tabular}{c|l}
\hline Abbreviation & \multicolumn{1}{c}{ Meaning } \\
\hline $\mathbf{1 m} / \mathbf{1 w}$ & $\begin{array}{l}\text { Negligible level of aggressiveness in } \\
\text { men / in women } \\
\text { Quite low level of aggressiveness in } \\
\text { men / in women } \\
\text { Low level of aggressiveness in men / in } \\
\text { women } \\
\mathbf{3 m} / \mathbf{3 w}\end{array}$ \\
$\mathbf{4 m} / \mathbf{4 w}$ & $\begin{array}{l}\text { Neutral level of aggressiveness in men } \\
\text { / in women } \\
\text { Quite high level of aggressiveness in } \\
\text { men / in women } \\
\text { High level of aggressiveness in men / } \\
\text { in women } \\
\text { Very high level of aggressiveness in } \\
\text { men / in women }\end{array}$ \\
\hline
\end{tabular}

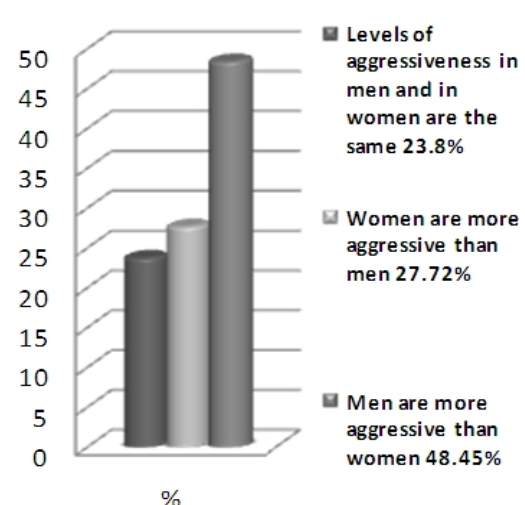

Fig. 2. Levels of male and female aggression. Women's perception.

More than $58 \%$ of men consider themselves as more aggressive than women, while $48 \%$ of women share their opinion. The opposite point of view is held by almost $28 \%$ of women and only $16 \%$ of men. By $23.8 \%$ of women and $25.3 \%$ of men male and female aggression was estimated as equal (Fig. 2, Fig. 3).

Thus, in the Russian-speaking society in general men are believed to be more aggressive, but at the same time women evaluate both genders as more aggressive than men do.

In the recent study our goal was to look if the prevailing beliefs affect the immediate perception, which should be reflected in the assessment of aggressiveness of separate units of communicative information.

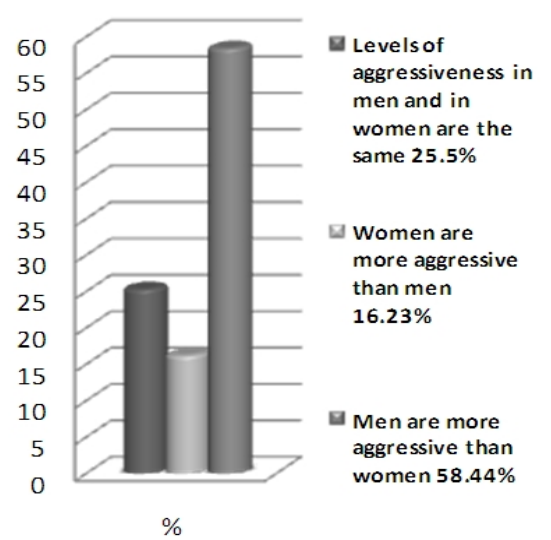

Fig. 3. Levels of male and female aggression. Men's perception.

\section{DESCRIPTION OF THE STUdY PROCESS}

\section{A. Participants}

The study involved 248 people in age 20-79 years (mean 24.6 years), 100 men and 148 women. In men, the age spread in the sample 20 - 79 years, mean - 25.9 years. In women, the age spread in the sample 20 - 53 years, mean - 23.7 years.

\section{B. Method}

We created a computer program, consisting of the page for demographic information and the experimental part - a set of 20 aggressive and 16 non-aggressive audio phrases in male and female voices, so that half of the sample had heard one phrase in a man's voice, and half in a female's. All phrases were recorded on audio by professional actors, in male and female voices. The actors were instructed to read sentences with a relatively neutral intonation, since our goal was to create the conditions of a maximum uncertainty for enhancing a projective freedom.

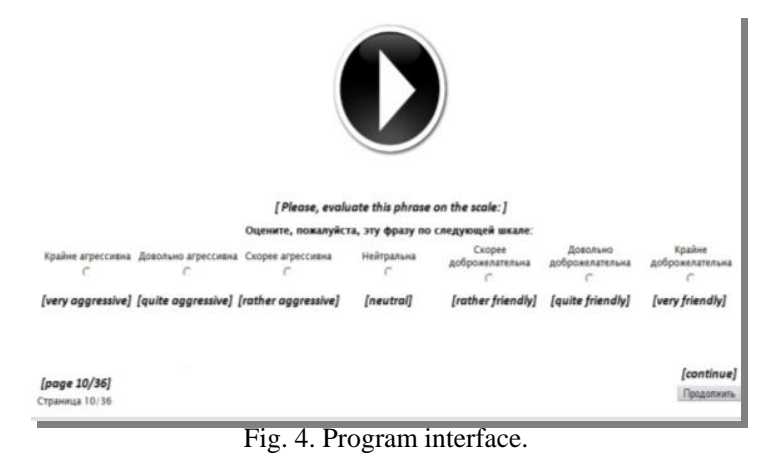

Gender, used in phrases, was in the direct correspondence with a participant's gender to enhance the effect of identification. 
Aggressive phrases included threats, commands and the expression of negative attitudes. Both aggressive and non-aggressive groups contained the phrase addressing with "you" (singular), "you” (plural, respectful form in Russian), phrases with hidden addressing, and phrases about a third person.

All phrases were presented in random order and participants were asked to evaluate each stimulus on the seven-step Likert scale, from "very aggressive" to "very friendly" (Fig. 4).

\section{Processing of the Results}

As raw data we obtained answers to each stimulus. Estimates were given the values of 1 ("very aggressive") to 7 ("very friendly"). Then a new variable (1) has been created, which reflects the average response on the scale:

$$
\frac{\sum_{i=1}^{n} a_{i}}{n}
$$

where: $n$ - number of stimuli in a group, $a$ - an estimate on the scales.

Average scores were calculated for responses to each of the stimuli in the following groups: men who have heard the phrase in a male voice, in a female voice, women who have heard the phrase in a female voice, in a male voice.

\section{RESULTS}

Two complementary series of comparisons were conducted.

The first one was comparing the mathematical differences of estimates of phrases in a female voice and in a male voice, women (Fig. 5, combined with Table II) and for men (Fig. 6, combined with Table II). For each question, we compared the differences FV - MV (where FV = mean score for phrase in female voice, $\mathrm{MV}=$ mean score for phrase in male voice). If the difference was negative, it was marked as -1 , if positive as 1 . After that step, the phrases were grouped based on their aggressiveness or non-aggressiveness, aiming at finding systematic differences in the perception of certain type of phrases.

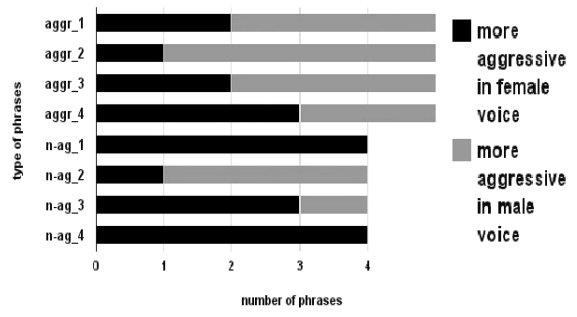

Fig. 5. Comparison of male and female voices: women.

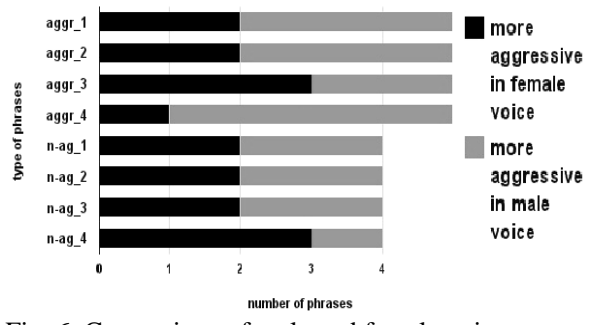

Fig. 6. Comparison of male and female voices: men.
TABLE II: ABBREVIATIONS USED IN FIG. 5, FIG. 6

\begin{tabular}{c|l}
\hline Abbreviation & \multicolumn{1}{c}{ Meaning } \\
\hline aggr_1 & $\begin{array}{l}\text { Aggressive phrases } \\
\text { with hidden addressing } \\
\text { Aggressive phrase } \\
\text { addressing with "you" (singular) } \\
\text { Aggressive phrases } \\
\text { about a third person } \\
\text { Aggressive phrase } \\
\text { addressing with "you" (plural) }\end{array}$ \\
aggr_4 & $\begin{array}{l}\text { Non-aggressive phrases } \\
\text { with hidden addressing } \\
\text { Non-aggressive phrase } \\
\text { addressing with "you" (singular) } \\
\text { n-ag_2 }\end{array}$ \\
n-ag_3 & $\begin{array}{l}\text { about a third person } \\
\text { Non-aggressive phrase } \\
\text { addressing with "you" (plural) }\end{array}$ \\
\hline
\end{tabular}

In the second series for each question we compared difference between men's and women's scores for questions in a male voice and in a female voice: $F S-M S$ (where $F S=$ mean women's score, $M S=$ mean men's score) (Fig. 7, Fig. $8)$.

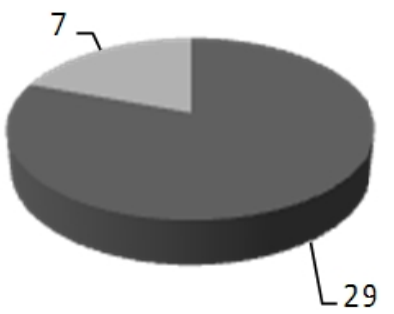

women evaluate as more aggressive

men evaluate as more aggressive

Fig. 7. Comparison of male and female estimates of aggression for phrases in male voice.

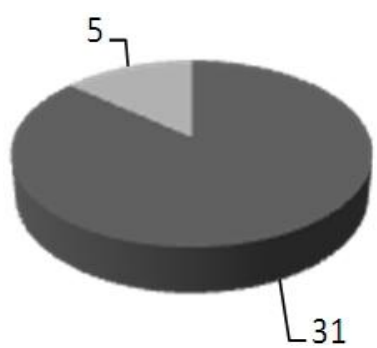

women evaluate as more aggressive

men evaluate as more aggressive

Fig. 8. Comparison of male and female estimates of aggression for phrases in female voice.

It has been shown that women in general evaluate phrases as more negative, than men do; both in male $(p=0.0002)$ and female $(p<0.0001)$ voices.

At the same time, six out of seven phrases in a male voice that women perceived as more friendly than men did, are non-aggressive phrases; out of the 16 non-aggressive phrases 12 sound for women more friendly in a male voice. For aggressive phrases this effect was not observed. For men, this effect is not observed.

Based on these results we can conclude that non-aggressive phrases are perceived by women as more friendly when they are said in a male voice $(p<0.05)$.

Thus, the experimental verification confirmed the women peculiarity to evaluate communicative information generally as more aggressive than men. The found earlier common belief that men are more aggressive than women is not reflected in the perception of aggressive messages. The tendency to perceive the aggressiveness of their own gender as higher than it is in the perception of the opposite gender 
manifested in the detected women peculiarity to perceive aggressive phrases as more friendly if they are pronounced in a male voice.

\section{CONCLUSION}

Social stereotypes have an impressive impact on the direct perception of the communicative information. The results of the presented work shed light on gender differences in the perception of pronounced aggressive and non-aggressive communicative information, and indicate the relationship between common beliefs about aggressiveness and direct perception of aggressive and non-aggressive communicative information.

In addition to the academic value in the call to the field of perception of aggression as a whole and particularly to gender differences in the perception of aggression, these results will be also interesting for the media field, and can be widely used in the development of various technologies, that include human computer interaction component, from computer assisted learning systems to cell phones and navigation devices.

\section{REFERENCES}

[1] L. Berkowitz, Aggression: Its causes, consequences, and control, Mcgraw-Hill Book Company, 1993.

[2] D. Zillmann, Hostility and Aggression, Erlbaum, N.J.: Hillsdale, 1979

[3] R. Baron and D. Richardson, Human Aggression, Springer, 2004, ch. 1.

[4] J. D. Coie and K. A. Dodge, "Aggression and antisocial behavior," Handbook of Child Psychology, Social, Emotional And Personality Development, vol. 3, 1997.

[5] L. Jianghong, "Concept analysis: Aggression," Mental Health Nursing, vol. 25, issue 7, pp. 693-714, 2004.

[6] S. G. Sukiassian, Aggression: The Nature Human Aggressiveness, Moscow: Prime-Evroznak, 2003.

[7] D. J. Albert, M. L. Walsh, and R. H. Jonik, "Aggression in humans: What is its biological foundation," Neuroscience and Biobehavioral Reviews, vol. 17, no. 4, pp. 405-425, 1994.

[8] D. Behar, J. Hunt, A. Ricciuti, D. Stoff, and B. Vitiello, "Subtyping aggression in children and adolescents," The Journal of Neuropsychiatry \& Clinical Neurosciences, vol. 2, pp. 189-192, 1990.

[9] J. E. McElliskem, "Affective and Predatory Violence: A Bimodal Classification System of Human Aggression and Violence," Aggression \& Violent Behavior, vol. 10, pp 1-30, 2004.

[10] A. H. Buss, The psychology of aggression, Hoboken, NJ, US: John Wiley\& Sons Inc., 1961.

[11] C. E. Izard, The Psychology of Emotions, Springer, 1991.

[12] G. Roth and D. Strüber, "Neurobiological aspects of reactive and proactive violence in antisocial personality disorder and "psychopathy"," Prax Kinderpsychol Kinderpsychiatr, vol. 58, issue 8, pp. 587-609, 2009.

[13] S. Pogun, "Sex differences in brain and behavior: Emphasis on nicotine, nitric oxide and place learning," International Journal of Psychophysiology, vol. 42, issue 2, pp. 195-208, 2001.

[14] J. Archer, "Sex differences in aggression in real-world settings: A meta-analytic review," Review of General Psychology, vol. 8, issue 4, pp. 291-322, 2004

[15] A. H. Eagly and V. J. Steffen, "Gender and aggressive behavior: A meta-analytic review of the social psychological literature," Psychological Bulletin, vol. 100, issue 3, pp. 309-330, 1986

[16] Y. Shcherbinina, Verbal Aggression, Moscow: Kom Kniga, 2006.

[17] S. P. Springer and G. Deutsch, "Left brain, right brain: Perspectives from cognitive neuroscience," Journal of Psychophysiology, vol. 14, pp. 50-52, 1998 .

[18] K. Bjorkqvist, "Sex differences in physical, verbal, and indirect aggression: A review of recent research," Sex Roles, vol. 30, issue 3-4, pp. 177-188, 1994.

[19] S. Byrne, Gender Psychology, St. Petersburg: Prime Evroznak, 2001.

[20] E. A. Ivanova, "Gender differences in the manifestation of aggression in adolescents," Siberian Psychological Journal, vol. 21, pp. 85-88, 2005.
[21] Ch. Mims. (July 5, 2007). Strange but true: Testosterone alone does not cause violence. [Online]. Available: http://www.scientificamerican.com/article.cfm?id=strange-but-true-te stosterone-alone-doesnt-cause-violence

[22] R. A. Josephs and P. H. Mehta, "Testosterone and Cortisol jointly regulate dominance: Evidence for a dual-hormone hypothesis," Hormones and Behavior, vol. 58, issue 5, pp. 898-906, 2010.

[23] P. B. Gray, P. T. Ellison, and B. C. Campbel, "Testosterone and marriage among Ariaal men of northern Kenya," Current Anthropology, vol. 48, issue 5, pp. 750-755, 2007.

[24] P. B. Gray, J. C. Parkin et al., "Hormonal correlates of human paternal interactions: A hospital-based investigation in urban Jamaica," Hormones and Behavior, vol. 52, issue 4, pp. 499-507, November 2007.

[25] A. Abbott, "Testosterone link to aggression may be all in the mind," Nature News, 2009.

[26] F. Brambilla, A. Speca, I. Pacchiarotti, and M. Biondi, "Hormonal background of physiological aggressiveness in psychologically healthy women," International Journal of Psychophysiology, vol. 75, issue 3, pp. 291-294, March 2010.

[27] S. Bennett, D. P. Farrington, and L. R. Huesmann, "Explaining gender differences in crime and violence: The importance of social cognitive skills," Aggression and Violent Behavior, vol. 10, issue 3, pp. 263-288, 2005.

[28] J. Archer, "Sex differences in aggression between heterosexual partners: A meta-analytic review," Psychological Bulletin, vol. 126, issue 5, pp. 651-680, 2000

[29] J. Archer, "Cross-cultural differences in physical aggression between partners: A social-role analysis," Personality and Social Psychology Review, vol. 10, no. 2, pp. 133-153, 2006

[30] D. G. Dutton and T. L. Nicholls, "The gender paradigm in domestic violence research and theory: Part 1: The conflict of theory and data," Aggression and Violent Behavior, vol. 10, issue 6, pp. 680-714, 2005.

[31] A. A. Kuzminykh and S. N Enikolopov, "Prevailing perceptions of masculine and feminine aggression," Psychological Science and Education, vol. 5, pp. 70-80, 2011.

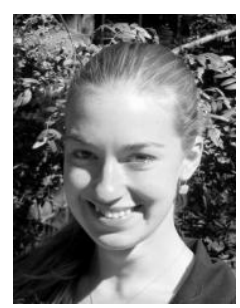

Anastasia A. Kuzminykh was born in Pushchino, Russia in 1990. In 2012, she graduated from the Lomonosov Moscow State University, Moscow, Russia, with Specialist Degree (equivalent of master's degree) in clinical psychology.

In 2007-2009 she was a REPORTER, contributing to a weekly column covering science news at the Journal "Russian Reporter", Moscow, Russia. In 2009-2010 she was a lecturer in physiological psychology at Lyceum \#1553, Moscow, Russia. She supervised a team of high school students carrying out various projects in the field of physiological psychology. In 2011 she was an instructor and curriculum developer for the center of bilingual education London Gates Education Group, pre-schoolers project. She was working as a lecturer in Russian Language at the Department of Germanic and Slavic Studies, University of Waterloo, Canada, and as a RESEARCH ASSISTANT at the Computer Assisted Language Learning Project, University of Waterloo, Canada. She is now a graduate student at the Department of System Design Engineering, University of Waterloo, Canada. Her research interests include psychology of aggressiveness, psychology of perception, psychology of emotions, social psychology, and human computer interaction.

Ms. Kuzminykh was a laureate of The Russian Federation presidential award for support of talented youth in 2007, winner of the Vernadsky National Contest of Student Research Projects in 2006, winner of the International Scientific Conference of Student Research Projects "Kolmogorov reading" in 2006, awarded the Medal "The Winner of contests and competitions" in 2006.

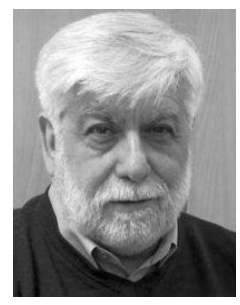

Sergey N. Enikolopov was born in Yerevan, Armenia in 1948. In 1972, he graduated from the Lomonosov Moscow State University, Moscow, Russia, with specialist degree (equivalent of master's degree) in psychology. In 1984-PhD in legal psychology on "Aggression and aggressiveness of violent criminals". In 1989 became the HEAD of the Laboratory of psychosocial research at the Medical Health Research Center RAMS and became an assistant Professor at the Department of Neuropsychology and Abnormal Psychology at the Lomonosov Moscow State University. 1996-2001 was the HEAD of the Department of Clinical Psychology at the Sholokhov Moscow State Humanitarian University. In 1998 he became the HEAD of the Division of 
Clinical Psychology at the Medical Health Research Center of the Russian Academy of Medical Sciences. In 2005 he HEADED the Department of the Criminal psychology at the Moscow City University of Psychology and Education. He is now the HEAD of the Division of Clinical Psychology at the Medical Health Research Center RAMS, Moscow, Russia, ASSISTANT PROFESSOR at the department of neuropsychology and abnormal psychology at Lomonosov Moscow State University, Moscow, Russia, and the HEAD of the department of criminal psychology at the Moscow City University of Psychology and Education, Moscow, Russia. He was one of the first researchers of criminal aggression in Russia. His research interests include psychosomatic, psychology of aggressive behavior, psychology of victimization, psychology of humor, ethnopsychology.
Dr. Enikolopov is a member of the Moscow branch of the Russian Society of Psychologists, a member of the Russian Society of Psychiatrists, a member of the Russian Criminological Association, a member of the International Society for the Study of Aggression (International Society for Research on Aggression, ISRA), full Member (Academician) of the Russian Academy of Medical and Technical Sciences. He is a member of the editorial boards of the journals: "Psychiatry", "Psychology and Law", "Armenian Journal of Mental Health", "Medical psychology in Russia". Awards: Medal "In memory of the 850th anniversary of Moscow" in 1998, G.I. Chelpanov Medal "For contribution to the development of psychological science» in 2008. 